\title{
Educación, movimientos sociales y comunicación popular: reflexiones a partir de experiencias en Uruguay*
}

\author{
Pablo Leandro Díaz
}

Universidad de la República, Montevideo, Uruguay. Email: diazpablouruguay@gmail.com

\section{Víctor Adrián Díaz}

Universidad Bolivariana, Santiago, Chile. E-mail: victoradriandiaz@gmail.com

Resumen: Los movimientos sociales (MS) son acciones colectivas reiteradas, de confrontación o desborde de las instituciones, con expresiones más o menos organizadas en torno a una reivindicación. Acciones sostenidas de reclamos y demandas, que no se identifican con las instituciones que los generan. La comunicación desde la perspectiva del sujeto se convierte en vehículo de las demandas. La comunicación popular fortalece la acción colectiva interna, mientras que, por otro lado, los medios masivos desarticulan la imagen de los sujetos enfatizando sus intereses al servicio de empresas, corporaciones y conglomerados. Algunas experiencias en el medio rural uruguayo, nos permiten reflexionar: ¿Es posible que los MS sean espacios educativos y constituyan sujetos pedagógicos? ¿Qué función cumple la comunicación popular al interior y al exterior de los MS? ¿Cómo abordar a los medios masivos que banalizan y distorsionan la lucha de los MS? El estudio de los MS ¿es una tarea académica o militante? dagógicos.

Palabras clave: movimientos sociales, comunicación popular, sujetos pe-

\section{Education, social movements and popular communication: Analysis springing from experiences in Uruguay}

\begin{abstract}
Social movements (SM) are repeated collective actions, of confrontation or institutional overflowing, with expressions more or less organized related to a claim. Sustained actions on claims and demands, which do not identify with the institutions that generate them. The communication from the perspective of the subject becomes a vehicle of the claims. Popular communication strengthens the internal collective action, while, on the other hand, the mass media dismantle the image of the subjects emphasizing their interest in the service of firms, corporations and conglomerates. Some experiences in rural Uruguayan allow us to think: Is it possible that SM are educational spaces and constitute educational subjects? What role does popular communication has inside and outside the SM? How can we deal with the media that trivialize and distort the struggle of SM? The study of SM, is it an academic task or an activist task?
\end{abstract} subjects.

Key words: social movements, popular communication, pedagogic 


\section{Educação, movimentos sociais e comunicação popular, pensamentos com base em experiências no Uruguai}

Resumo: Os movimentos sociais (MS) sao ações coletivas que se repetem, de confronto ou transborde institucional com expressões mais ou menos organizadas em torno de uma reivindicação. Ações de reivindicações e demandas, que não se identificam com as instituições que os geram. A comunicação a partir da perspectiva do sujeito se torna um veículo das reivindicações. A comunicação popular fortalece a ação coletiva interna, enquanto, por outro lado, as mídias de massa desmontam a imagem do tema enfatizando o seu interesse para as empresas de serviços, corporações e conglomerados. Algumas experiências no Uruguai rural permitir-nos a refletir: É possível que os MS sejam atividades educativas e constituam-se como sujeitos educacionais? Qual é o papel da comunicação popular dentro e fora do MS? Como lidar com as mídias que banalizam e distorcem a luta do MS? O estudo dos MS é uma tarefa acadêmica ou ativista? dagógicas.

Palavras-chave: movimentos sociais, comunicação popular, questões pe-

El Tribunal de la Historia se nutre, en primer lugar de la auténtica memoria social y de la legítima rebelión cívica. Y se nutre, en segundo lugar, de la cultura solidaria e igualitaria engendrada en el propio vientre del movimiento cívico de rebelión.

Gabriel Salazar V. (2009)

\section{Introducción}

Los Movimientos Sociales (MS) en Uruguay son un área de estudio poco explorada. ${ }^{1}$ Sin embargo, en América Latina a comienzos del siglo XXI, aumentó vertiginosamente la producción de trabajos académicos, a pesar de poseer ciertos límites como: la fragmentación, el ensimismamiento y la recurrencia de perplejidades conceptuales (Ibarra, 2000).

Sin ahondar en aspectos generales, nos proponemos discutir algunas preguntas de carácter reflexivo sobre los movimientos sociales y las articulaciones entre educación y comunicación, a partir de Paulo Freire y las prácticas educativas en el medio rural del norte uruguayo. ${ }^{2}$

$¿$ Es posible que los movimientos sociales (MS) sean espacios educativos y que además constituyan sujetos pedagógicos, a través de la educación, como práctica productora de sujetos? ¿Qué sujetos se forman en los MS? ¿Qué papel cumple la comunicación popular al interior y al exterior de los MS? ¿Cómo abordar a los medios masivos que banalizan y distorsionan la lucha de los MS? El estudio de los MS ¿es una tarea académica o militante? 
Sin ánimo de agotar la discusión y responder a todos los interrogantes, intentaremos en estas palabras, tensionar la pertinencia de analizar una posible línea de investigación sobre MS en Uruguay a partir de sus "síntomas”, desde disciplinas como la educación (educación popular) y la comunicación (comunicación popular).

\section{Investigación, docencia y extensión en el "ciclo del conocimiento"}

Paulo Freire ubica dos cuestiones interesantes sobre las cuales discutir las prácticas de extensión universitaria: la cuestión política (que también es pedagógica) y la cuestión epistemológica, ambas concatenadas (Freire, 1998).

Frente a la decisión política, el hecho de involucrar la Universidad “al servicio de los intereses populares” es una opción progresista coherente que no implica pérdida de rigurosidad en cuanto al conocimiento, como tampoco implica incompetencia. Por el contrario implica mayor profundización y articulación de los diversos momentos del ciclo del conocimiento, y mayor criticidad en la búsqueda de articular el saber científico y el saber popular.

El "ciclo del conocimiento" implica: producir el conocimiento (preponderantemente investigar), y conocer "el conocimiento ya existente" (enseñar-aprender, preponderantemente el momento de la docencia). Siendo la práctica de extensión una posibilidad de democratizar el conocimiento universitario sin que pierda su valor académico, quedando implícita la necesidad de la integración de las tres tareas de la universidad dentro de una definición política progresista y popular.

\section{La hipótesis de Touraine: "prehistoria de los MS en América Latina"}

En conferencias de sociología latinoamericana, Alain Touraine (19971998), ha valorizado la definición de sujeto como centro de la vida social moderna, a fin de explicar las relaciones sociales en las que este sujeto afirma su autonomía y se tensiona con su manipulación como objeto, consumidor, votante o público, de los centros de poder. De allí que el sujeto se liga al movimiento social, al ser portador de un sentido moral para la sociedad, al defender su libertad y sus derechos, al oponerse a ciertos procesos de modernización que enfatizan la racionalización (sobre todo instrumental ) por encima de la subjetivación, lo que parcializa la modernidad.

Pensando en el caso latinoamericano, Touraine, considera que los MS empiezan a surgir como actores sociales a fines del siglo XX con la 
emergencia de diferentes movimientos autónomos. De allí señala que Latinoamérica se encuentra en la “víspera de los MS” (Touraine, 1997), a medida que los regímenes nacionales y populares diferencian sus funciones internas. La debilidad de los actores sociales en los regímenes nacionales-populares se explica por la fortaleza de los actores vinculados al Estado.

En los últimos años, al afianzarse el sistema político bajo un período de régimen democrático y al detectarse la rotación de los diferentes partidos en los gobiernos de la región (sistema de partidos), varias demandas populares relegadas son planteadas mediante acciones que desbordan las instituciones representativas, así como son reafirmadas ciertas reivindicaciones, aprovechando oportunidades políticas abiertas por partidos “amigos” de los movimientos. Las acciones colectivas no reguladas son emergentes de demandas sociales autónomas, y que no necesariamente se identifican con las instituciones u organizaciones “amigas” que las impulsan. A fines del siglo XX y principios del XXI, en América Latina el Ejército Zapatista de Liberación Nacional (EZLN) de México, el Movimento dos Trabalhadores Rurais Sem Terra (MST) de Brasil, los cocaleros de Bolivia, los campesinos de Argentina, los estudiantes de Enseñanza Media "Pingüinos” en Chile y los desocupados febriles o desempleados de empresas trasnacionales en América Latina, se organizan colectivamente a partir de demandas sociales, desvinculadas de intereses político-partidarios, institucionales o corporativos. Estas acciones colectivas de los sujetos conforman y construyen sus propias identidades a partir de sus reclamos y a la vez, evitan condicionar sus decisiones frente a los intereses de las instituciones afines, que en ocasiones las amparan.

\section{Acciones Colectivas en América Latina y también en Uruguay}

En el siglo XIX se hablaba de movimiento social como sinónimo de movimiento obrero (entendiendo por tal a la acción de sindicatos y grupos políticos anarquistas y de izquierda), hoy en día el movimiento obrero en varios países, está conformado por grupos de presión o formas de acción institucionalizada o tan ligadas a los partidos de izquierda que difícilmente sean considerados movimientos sociales. Para ciertos autores los movimientos anticoloniales y de liberación nacional, fueron claramente movimientos sociales anti-sistémicos.

Luego del Mayo Francés '68, mientras se hablaba de una "nueva izquierda”, los estudiosos de los movimientos sociales de los '70 y '80 consideraban que existían “viejos” y "nuevos movimientos sociales”, una forma de marcar la distinción entre la acción rutinaria de la izquierda tradicional y burocrática (formas convencionales de protesta), y la innovación del accionar del movimiento ambientalista, feminista y pacifista, o de las minorías raciales y étnicas. 
Immanuel Wallerstein (2007) considera que es a partir del Foro Social Mundial de Porto Alegre que se puede hablar de la existencia de un movimiento social anti- sistémico distinto. Sin embargo cabe destacar que el movimiento obrero tradicional tuvo y tiene una destacada participación en estos espacios de globalización de movimientos, conviviendo con organizaciones alter-mundialistas, ONGs, campesinos, indígenas, movimientos por la diversidad sexual, minorías raciales, ecologistas, entre otras.

En el campo disciplinar de la sociología existen actualmente dos escuelas: una europea del movimiento social (Alain Touraine y Alberto Melucci), y otra escuela norteamericana ("teoría de movilización de recursos”, con una fuerte influencia de Charles Tilly y Sidney Tarrow). Pero también existen varias corrientes latinoamericanas emergentes (territorialidad de la geografía brasileña, marxista de la sociología, etc.). Dependerá de la definición de MS y de la corriente sociológica a considerar lo productivo que pueda resultar una línea de investigación que considere a los MS.

La hipótesis para descartar, refutar o confirmar nuestra línea de investigación sobre MS en Uruguay, se enfoca en los propios síntomas uruguayos de dichas acciones, entendidos como acciones colectivas disruptivas o de confrontación con las instituciones que se sostienen en el tiempo, que se desbordan y empuñan demandas sociales autónomas, a partir de conflictos protagonizados por organizaciones sociales o conflictos en los que no intervienen organizaciones. Y que éstos "síntomas” según la definición que tomemos de movimiento social, y la escuela o biblioteca de autores en que nos basemos, podríamos considerarlos emergentes de una "prehistoria" de MS en Uruguay, en sintonía con la hipótesis de la "prehistoria" de estos actores colectivos que plantea Touraine para el caso latinoamericano.

\section{Acciones colectivas y educación popular}

Freire también señala que en los sectores populares la lucha de clases logra no sólo una aparición manifiesta sino también latente, escondida, oculta, en formas de resistencia que ha "llamado 'mañas' de los oprimidos, en el fondo 'inmunizaciones' que las clases populares van creando en su cuerpo, en su lenguaje, en su cultura”, de allí "la necesidad fundamental que tiene el educador popular de comprender las formas de resistencia de las clases populares, sus fiestas, sus danzas, sus juegos, sus leyendas, sus devociones, sus miedos, su semántica, su sintaxis, su religiosidad. No es posible organizar programas de acción político-pedagógica sin tomar seriamente en cuenta las resistencias de las clases populares” (Freire, 1996: 54).

El desafío que plantea la modernidad al ser humano como sujeto, es constituirse como actor -según Touraine-, complementando y oponiendo los avances de la racionalidad y el valor de su subjetividad: "los éxitos de la acción técnica no deben hacer olvidar la creatividad del ser humano" (Touraine, 1994: 205). 
Hablar de sujetos populares, cuestiona la modernidad colocando la pregunta por el sujeto que tiene conciencia de sí mismo y lo lleva a tener la voluntad de influir sobre el propio "yo y su circunstancia”, y a la vez asegura la extensión de su libertad mediante sus actos de protección (Salazar y Pinto, 1999: 93).

Es parte de la educación contemplar que los sujetos populares hacen cultura popular desde una mirada "pragmática y subalterna, con apertura dialógica y heterológica, como impulso material de accesibilidad y participación horizontal, con autocrítica y creatividad (...) de una forma de moverse más que de un espacio delimitado o un tipo de discurso específico” (Méndez, 2003: 149).

Este movimiento silencioso es invisibilizado y opacado por medios de comunicación masivos, empresas multinacionales, instituciones o conglomerados de medios. El neoliberalismo impone su lógica mediante la oferta del modelo individualista y consumidor: seres aislados, anónimos, poderosos y exitistas. Aquellos individuos “egoístas” e "insensibles” de la sociedad burguesa que pueden "inflarse hasta convertirse en átomos" y cuyas búsquedas se definen como "megalothymia"3 o hiperexitismo (Salazar, 2009: 264).

El carácter dinámico y social del sujeto popular, no sólo se resiste a estas prácticas, sino que gana 'negociaciones' silenciosas con el mercado, mediante la "invisibilidad” transitoria (Méndez, 2003). Son los MS, quienes a través de sus prácticas populares, protagonizan la comunicación como sujetos territoriales. Por su parte, los medios masivos y el rating son formas pretensiosas e ilusorias de "asujetar” al sujeto (Díaz, V., 2010: 27).

Las culturas populares centran sus búsquedas en la (re) construcción de comunidades de sentido y en la (auto) reafirmación de su/s identidad/es, exigiendo respeto en materia de derechos. Muchos de los casos son parte de una minoría étnica, sexual, religiosa, eco-social y cultural (Ibid: 13).

\section{Comunicación popular como herramienta colectiva}

La mirada comunicacional de los MS, se ve reflejada con el surgimiento de las Nuevas Tecnologías de la Información y la Comunicación (NTIC), de los '90, que ha permitido luchas y resistencias de colectivos sociales, especialmente a través de redes en la web. Los MS persiguen proyectos ligados al ámbito social, no tienen obligación de adherir a núcleos sectarios o político-partidarios, salvo que las organizaciones establecidas, exijan lo contrario.

Dos claros ejemplos, se pueden citar en América Latina: por un lado en 1994, el Ejército Zapatista de Liberación Nacional (EZLN) en Chiapas, México, con el comandante Marcos al frente, transformándose en el movi- 
miento social revolucionario, más pacífico de la historia, cuyas armas eran las redes creadas en Internet y las comunidades virtuales. Por otro lado, el Movimento dos Trabalhadores Rurais Sem Terra (MST) de Brasil, movidos por lemas como: "Reforma agraria: iPor Justiça Social e Soberania Popular!". Otro ejemplo que argumenta las prácticas comunicativas de los sujetos populares, es el caso de un grupo de jóvenes universitarios, principalmente de Montevideo, que en el año 2000, decidieron internarse en el Uruguay profundo hacia el Norte, frontera con Brasil, en la ciudad de Bella Unión. En un medio rural, caracterizado por situaciones de pobreza, desempleo, marginación, desnutrición infantil y analfabetismo, los jóvenes desde la pedagogía de la Educación Popular y la óptica transdisciplinaria, promueven el desarrollo local, la alfabetización rural, economía solidaria auto-sutentable y la organización sindical (Díaz, V., 2010: 11-12).

Los aspectos que desde la óptica comunicacional, comparten estas experiencias, tienen que ver con el fortalecimiento que desde las redes locales y virtuales han promovido las colectividades de sujetos. El intercambio de mensajes vía web, los fortaleció a tal punto que permitieron una comunicación en paralelo con los medios oficialistas, masivos y hegemónicos.

La comunicación popular, al interior de los MS, permitió la apropiación y reorganización de los colectivos, así como también la renovación y el fortalecimiento de su sentido de pertenencia, hacia la construcción de identidades.

Gabriel Salazar rescata el concepto de "poder popular constituyente" cuando habla del movimiento cívico popular que se anticipa al "ajusticiamiento político post-dictatorial”. Ese afán constructivo del colectivo debe primar, por sobre el "afán destructivo contra el enemigo" (Salazar, 2009: 287).

El autor propone el autoconocimiento del MS, como una de las estrategias para el fortalecimiento y mejora al interior del movimiento, empleando la comunicación oral como vehículo horizontal y espontáneo, centrado en el poder constituyente. Estas herramientas permiten prácticas legítimas, descontaminadas de intereses corporativos y panfletarios.

La comunicación popular es una herramienta que cruza el MS, no instituyente, lo fortalece, le permite generar espacios educativos, que al interior del colectivo se socializan, priorizando los niveles de propuesta ante el choque, la combatividad física, o la "técnica de la materialidad de sus símbolos” (canciones, grafitis, vestuarios, ritos, consignas, imágenes, etc.) (Salazar, 2009: 288).

Hablamos concretamente de un MS centrado en la imagen corporativa en oposición a aquellos, que procuran procesos internos, de renovación, cuestionamiento y autoevaluación, evitando el sectarismo, el tribalismo propio de los grupos herméticos. "El poder sociocultural del movimiento 
rebelde, aun cuando se transforme en 'constituyente', es, de todos modos, limitado. Tiene el poder corrosivo y a la vez persuasivo de lo que es justo, humano y legítimo (Salazar, 2009: 289).

La disrupción es una forma de pensar que parte de la idea de la interrupción y de la ruptura con los convencionalismos. Los MS son disruptivos, pero no necesariamente corporativos o instituyentes, es decir, no se identifican con marcas o slogans, centrándose en el poder constituyente. Esto significa no dependientes y por ende, gozan de ciertos niveles de autonomía.

En este mismo sentido, los medios de comunicación masivos, se apoderan del término comunicación y buscan la entretención y el rating, aunque sus discursos denigren la imagen de los sujetos populares. Esto se debe a que en sus orígenes, "algunos investigadores norteamericanos los denominaron: mass media, que significa medios masivos o de masas. Pero para legitimarse y afirmar su prestigio, los mismos empresarios, los denominaron: medios de comunicación social...” (Díaz, V., 2010:14).

Un ejemplo es la cobertura multimediática del conflicto con Argentina, acerca de la instalación de plantas de celulosa sobre el Río Uruguay, indicaba que la interrupción de los puentes internacionales, era un derecho (auto) atribuido al movimiento ecologista de Gualeguaychú (Entre Ríos). Sin embargo, razones políticas y económicas de peso (a nivel provincial y nacional), se cruzaban en el financiamiento de los famosos "piquetes" y las empresas millonarias de transporte internacional se beneficiaban con estas medidas.

Otro ejemplo es el rescate de los 33 mineros en Copiapó (Chile) entre agosto y noviembre 2010. El impacto multimediático logró aumentar la sintonía de las audiencias de todo el planeta. Aún después del rescate, los periodistas continuaban entrevistando a familiares, vecinos, conocidos y personas relacionadas con los mineros que, de la noche a la mañana se transformaron en héroes mediáticos.

El arte de "valerse de”, según De Certeau, no sólo les resultó útil a los medios, sino también a los 300 trabajadores de la mina San José que al finalizar el rescate, instalaron el "Campamento Esperanza 2", hasta que sus patrones cumplieran con el pago de sus salarios atrasados.

En el primer caso, los medios jugaron un papel crucial para los MS, como asociaciones colectivas más o menos organizadas, donde los intereses político-partidarios y económicos se entrecruzaron, sin evidenciar el nombre, la marca o el eslogan de la institución que los respaldaba y financiaba. En el segundo, los colectivos aprovecharon el suceso y la trascendencia del rescate, así como la atención de los medios, para reclamar por sus derechos de manera legítima, mediante acciones que no respondían a otros intereses, más que sus propias demandas. 


\section{Reflexiones finales}

Las acciones colectivas más o menos organizadas (aún sin llegar a adquirir la categoría de Movimiento Social), incluyen y adoptan a la educación popular como metodología de trabajo grupal y estrategia de funcionamiento interno. El autoconocimiento de los sujetos (como lo sugiere Salazar) ha mejorado la autocrítica y el resultado de las acciones.

Por su parte la comunicación popular también forma parte de estos procesos, en la medida en que sus objetivos permanecen centrados en la clara reivindicación de los derechos y demandas de los sujetos, sin inmiscuir intereses externos, de carácter institucional o corporativo, que culmine por empañar el sentido constituyente del colectivo.

En estos casos, Uruguay ha sido testigo de varias acciones colectivas que comenzaron con luchas y reclamos legítimos por parte de colectivos que lograron alcanzar sus objetivos iniciales, y más tarde, ante la distorsión mediática, políticos, empresarios y académicos de diversos bandos, motivados por intereses institucionales decidieron involucrarse en los procesos de los sujetos, apropiándose del resultado de sus acciones, para fines externos al colectivo.

¿Es posible que los movimientos sociales (MS) sean espacios educativos y que además constituyan sujetos pedagógicos, a través de la educación, como práctica productora de sujetos?

El movimiento sindical, por ejemplo, puede convertirse en un motor importante de promoción de los espacios de formación de los trabajadores rurales. La integración de la formación sindical, la educación básica, de educación agraria, con la formación política, otorgándoles la consistencia necesaria a la apuesta formativa de los sujetos en la lucha por la tierra y el mejoramiento de condiciones laborales.

¿Qué sujetos se forman en los MS? Los sujetos que luchan por sus derechos, se encuentran en movimientos circunstanciales, en algunos casos, necesitados de líderes conducentes a la feliz resolución de sus conflictos, a veces amenazados por las exigencias institucionales, otras ante la presión de los medios, alterando sus objetivos primordiales. Nuestras experiencias con los campesinos de Santiago del Estero, reflejan algunos aspectos educativos al interior del Movimiento:

“...como hemos demostrado con las experiencias del Movimiento Campesino de Santiago del Estero (MOCASE), la educación colabora en la formación de sujetos que participan de opciones políticas propias (como en el caso de este movimiento social donde los campesinos defienden ciertos proyectos políticos 'desde abajo', de resistencia y de construcción de alternativas ciudadanas” (Díaz, P., 2007: 170). 
¿Qué papel cumple la comunicación popular al interior y al exterior de los MS? La dicotomía masiva/popular, surge en el siglo XIX, ante las definiciones de "lo popular" como forma artesanal o folclórica. Sin embargo, la concepción de popular como sinónimo de masivo, fue apropiada por la cultura anglosajona, difundida y globalizada, así como el concepto de “redes sociales” o "medios de comunicación”.

El imperialismo cultural no se interrumpe con los procesos de transiciones democráticas en América Latina. Ante esto, la comunicación popular, al interior de los MS pasa a ser herramienta principal del proceso de "autoconocimiento" que le corresponde resolver a cada grupo o colectividad para superarse.

"Los sujetos de la comunicación popular son protagonistas. Su presencia y participación hace que las personas se apropien de los medios locales (radios comunitarias, periódicos barriales, TV local y alternativa; carnaval, teatro popular, etc.). Diseñan sus propios programas y alimentan el contenido con sus propuestas. Esto demuestra que el proceso de comunicación favorece la participación y la integración social” (Díaz, 2010: 42-43).

En América Latina, las prácticas otorgan la legitimidad de la comunicación popular. Autores como Mario Kaplún de Uruguay, Luis Ramiro Beltrán de Bolivia o Daniel Prieto Castillo de Argentina, se apoyaron en Paulo Freire para construir nuevas conceptualizaciones a partir de la sistematización de sus prácticas de educación popular con enfoque comunicacional, produciendo materiales didácticos, cuyo uso pedagógico contribuyó con la sociedad latinoamericana de los '80, en sus procesos de resistencia y transición democrática.

¿Cómo abordar a los medios masivos que banalizan y distorsionan la lucha de los MS? La cultura de la farándula y la mentira, distorsionan las realidades. En palabras de Ernesto Sábato: “la televisión es el opio del pueblo (...), uno va quedando aletargado delante de la pantalla, y aunque no encuentre nada de lo que busca lo mismo se queda ahí, incapaz de levantarse...” (Sábato, 2001: 14).

El ya mencionado caso de los 33 mineros, sirvió de carnada para la prensa internacional, logrando convertir el género informativo (antes objetivo e imparcial), en el género del entretenimiento, subjetivo (íntimo) y plenamente sesgado. La Televisión mundial transmitía una misma noticia, con muchos matices y creó historias paralelas. En Francia, la televisión abierta, transmitía con humor e ironía el rescate, satirizando lo que sucedía debajo de la mina San José cada uno de los días que permanecieron desaparecidos.

El uso que los medios masivos le dan a los acontecimientos ya dejó de ser novedad, para tornarse en el lugar común del efecto "chicle": estirar la noticia hasta el extremo. Por otro lado, aparecen, sujetos cuyas acciones 
colectivas se organizan apoyadas en el uso de las nuevas herramientas tecnológicas (como el caso de los Pingüinos en Chile con los teléfonos celulares).

El estudio de los MS ¿es una tarea académica o militante? Si bien, muchos de los interrogantes incluyen de manera implícita esta pregunta, tampoco es posible agotar las múltiples respuestas que de ella emanan. Nos reste rescatar que lo político y lo académico no son polos opuestos, sino complementarios. Durante varias décadas hemos contrapuesto lo teórico y lo práctico, o mejor dicho, la academia y las bases, como si fueran enemigos o aspectos disociados. Sin embargo, en pleno siglo XXI, resultaría imposible concebir un MS sin los aportes sustantivos de la academia y esta última, no podría avanzar sin el análisis de las experiencias.

Los estudios sobre MS arrojarían elementos sustantivos si la lucha política dentro de los mismos, se ejerce con legitimidad, autenticidad, solidaridad y ecuanimidad. En palabras de Salazar -citadas al comienzo-: "legítima rebelión cívica y cultura solidaria e igualitaria”. Estos aspectos excluyen a los MS de intereses instituyentes, conducentes al fracaso sostenidos por un frenético objetivo corporativo y exitista.

En una de las experiencias con trabajadores rurales del norte uruguayo, en Bella Unión, concluíamos que:

“...la lucha por la tierra, los asalariados y los pequeños productores se pueden formar en conjunto, logrando un salto cualitativo en plantear el reclamo de "tierra para trabajar" en el marco de un nuevo gobierno. La realización de talleres de formación, de respaldo a los procesos grupales de organización y de emprendimientos productivos solidarios, dan como resultado una síntesis profunda, una nueva mirada de quienes tienen los pies en la tierra sobre los caminos que se pueden transitar para avanzar en la reforma agraria” (Díaz, P., 2009: 65). 
Polis, Revista de la Universidad Bolivariana, Volumen 10, $N^{\circ} 28,2011$

\section{Notas}

* Ponencia presentada en el II Congreso Internacional de la Ciencias, la Tecnología y las Artes, Simposio $N^{\circ} 55$ “Acción Colectiva y Movimiento Social”, Usach, $1^{\circ}$ de noviembre de 2010, Chile.

${ }^{1}$ Los últimos años se centraron en la problemática político-ambiental respecto al conflicto con Argentina a propósito de la instalación de plantas de celulosa sobre el río Uruguay. Sin embargo, al 2010 son otras tantas las problemáticas que han llevado a los uruguayos a movilizarse colectivamente: tierra, salud, educación, vivienda, salarios, derechos humanos, género, veganismo, etc. Véase: uruguay.indymedia.org.

${ }^{2}$ Sectores rurales de Bella Unión y Tacuarembó desde el año 2000 hasta 2009 en un colectivo de extensión universitaria, inter-facultades, de la Universidad de la República (UDELAR). Si bien, no profundizaremos en dichas prácticas por razones de espacio, esta reflexión se apoya también en la investigación realizada en el noroeste argentino, sistematizada en: Díaz Estévez, Pablo (2007).

3 “Megalothymia” e “Isothymia” de Fukuyama -citado por Salazar (2009)-, ambos conceptos provienen del griego antiguo (Platón). Fukuyama lo emplea para caracterizar al hombre hiperexitoso de la sociedad estadounidense actual. Cualquier sistema que crea desigualdad política es necesariamente la alimentación de la "megalothymia” de algunos miembros (que se consideran superiores), mientras que niega a los demás. La democracia liberal, sugiere, que puede satisfacer la "isothymia" de todas las personas al mismo tiempo, sin crear conflicto, dejando "megalothymia” sólo en el ámbito de la economía. Véase Fukuyama, Francis: El fin de la historia y el último hombre. Buenos Aires: Planeta, 1992, V parte). 


\section{Bibliografía}

Consejo de Educación de Adultos de América Latina (1998), “A contribuiçao de Paulo Freire no debate sobre a refundamentaçao da Educaçao Popular", Revista de Educaçao, AEC, Año 27, No. 106 - enero/marzo de 1998, p.21.

Díaz, Víctor A. (2010), Soberanía de la Comunicación Popular en América Latina. Unión Gráfica, Bogotá.

Díaz, Pablo L. (2007), Tierra y Educación en el campesinado de Santiago del Estero. Nuestra América, Buenos Aires.

Ídem (2009), "Espacios para la formación colectiva del trabajador rural" (art.) En: Díaz, Pablo (comp.) Ampliando Saberes II. Praxis Rural en Bella Unión. Montevideo: Facultad de Humanidades y Ciencias de la Educación, UDELAR, pp. 56-65.

Freire, Paulo (1970), Pedagogía del oprimido. Tierra Nueva, Montevideo. Ídem (1991), Política y Educación. Siglo XXI, México.

Ídem (1998), Pedagogía de la Esperanza. Un reencuentro con la Pedagogía del oprimido. Siglo XXI, Madrid.

Ídem (2001), Extensión o comunicación. La concientización en el medio rural. Siglo XXI, México.

Ídem (2003), El grito manso. Siglo XXI, Buenos Aires.

Ibarra, Pedro (2000), "Los estudios sobre los movimientos sociales: estado de la cuestión. Revista Española de Ciencia Política. Vol. 1. Núm. 2, abril de 2000, pp. 271-290.

Kaplún, Mario (1987), El comunicador popular. Ed. Humanitas, Buenos Aires.

Méndez Rubio, Antonio (2003), La apuesta invisible: Cultura, globalización y crítica social. Montesinos, España:

Sábato, Ernesto (2001) La resistencia., Seix Barral, Buenos Aires.

Salazar, G. y Pinto, J. (1999), Historia contemporánea de Chile II, actores identidad y movimiento. Lom,. Santiago de Chile.

Salazar, Gabriel (2009), Del poder constituyente de asalariados e intelectuales (Chile, siglos XX y XXI), Lom,. Santiago de Chile.

Touchard, Jean (1971), Historia de las ideas, Serie del Ciclo Básico Nº 13, Caps. XII a XVII, FCU, Montevideo. 
Touraine, Alain (1994), Crítica de la modernidad. FCE, Buenos Aires.

Ídem (1997), “De la mañana de los regímenes nacional-populares a la vís-

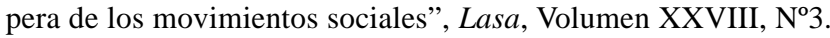

Wallerstein, Immanuel (2007), Crítica del Sistema-Mundo Capitalista. Era, México.

Recibido: 24.01.2011

Aceptado: 03.03.2011 